\title{
Associations of the metabolic syndrome and its components with cognitive impairment in older adults
}

Insa Feinkohl ${ }^{1 *}$ D, Jürgen Janke ${ }^{1}$, Daniel Hadzidiakos ${ }^{2}$, Arjen Slooter $^{3}$, Georg Winterer $^{2}$, Claudia Spies $^{2}$ and Tobias Pischon ${ }^{1,2,4}$

\begin{abstract}
Background: The metabolic syndrome (MetS) is an established cardiovascular risk factor. Here, we investigated its role in cognitive impairment.

Methods: Baseline data from 202 participants (aged 65 to 87 years) of the BioCog study were used. All were free of clinical dementia (MMSE $224 / 30$ ). Cognitive impairment was defined as the lowest tertile of a cognitive summary score. Multiple logistic regression analyses examined associations of body mass index (BMI), triglycerides (TG), high-density lipoprotein (HDL-C), glucose and glycated hemoglobin A1c ( $\mathrm{HbA1c}$ ) levels with the odds of cognitive impairment. MetS was defined as $\geq 3$ of its 5 components obesity (BMl $\geq 30 \mathrm{~kg} / \mathrm{m}^{2}$ ), elevated TG (TG $\geq 1.7 \mathrm{mmol} / \mathrm{L}$ ), reduced HDL-C (males: $<1.0 \mathrm{mmol} / \mathrm{L}$; females: $<1.3 \mathrm{mmol} / \mathrm{L}$ ), elevated glucose (glucose $\geq 5.5 \mathrm{mmol} / \mathrm{L}$ and/or diagnosed diabetes) and elevated blood pressure (history of hypertension). Analyses controlled for age, sex and smoking history.

Results: Lower HDL-C was significantly associated with a higher odds of cognitive impairment (OR 2.70 per $1 \mathrm{mmol} / \mathrm{L}$ reduction; $95 \% \mathrm{Cl} 1.25,5.56 ; p=0.011$ ), whereas $\mathrm{BMl}, \mathrm{TG}$, glucose and HbA1c were not (all $p>0.05$ ). Results for HDL-C were similar when HDL-C, glucose, BMI and TG were entered into a single model (OR 2.56 per $1 \mathrm{mmol} / \mathrm{L}$ reduction, $95 \% \mathrm{Cl} 1.09,5.88, p=0.031)$ and when cerebrovascular disease and coronary heart disease were additionally controlled for (OR 2.56 per $1 \mathrm{mmol} / \mathrm{L}$ reduction, 95\% Cl 1.06, 6.25, $p=0.036$ ). Among the 5 MetS components, participants with elevated TG were at 2-fold increased odds of impairment (OR 2.09, 95\% Cl 1.08, 4.05, $p=0.028$ ) including when the remaining 4 MetS components were entered $(\mathrm{OR} 2.23,95 \% \mathrm{Cl} 1.07,4.65, p=0.033)$, but the finding was no longer statistically significant when cerebrovascular disease and coronary heart disease were additionally controlled for $(p=0.11)$. Presence of MetS and of obesity, reduced HDL-C, elevated glucose or elevated blood pressure were not significantly associated with impairment (all $p>0.05$ ).
\end{abstract}

Conclusion: Our findings support low HDL-C as an independent risk marker of cognitive impairment in older age. The need for research into mediatory and confounding factors, and re-evaluation of traditional cut-off points is highlighted.

Trial registration: The study was registered on 15th October 2014 at clinicaltrials.gov (NCT02265263).

Keywords: Cognitive impairment, Epidemiology, High-density lipoprotein, Glucose, Metabolic syndrome, Triglycerides

\footnotetext{
* Correspondence: insa.feinkohl@mdc-berlin.de

${ }^{1}$ Molecular Epidemiology Research Group, Max-Delbrueck-Center for

Molecular Medicine in the Helmholtz Association (MDC), Berlin, Germany

Full list of author information is available at the end of the article
}

(c) The Author(s). 2019 Open Access This article is distributed under the terms of the Creative Commons Attribution 4.0 International License (http://creativecommons.org/licenses/by/4.0/), which permits unrestricted use, distribution, and reproduction in any medium, provided you give appropriate credit to the original author(s) and the source, provide a link to the Creative Commons license, and indicate if changes were made. The Creative Commons Public Domain Dedication waiver (http://creativecommons.org/publicdomain/zero/1.0/) applies to the data made available in this article, unless otherwise stated. 


\section{Background}

The metabolic syndrome (MetS) is a cluster of metabolic abnormalities, including abdominal obesity, elevated blood pressure (BP), elevated blood glucose levels, low high-density lipoprotein cholesterol (HDL-C) levels, and elevated triglyceride (TG) levels, and is suggested to play a major role in the development of cardiovascular disease (CVD) and type 2 diabetes mellitus [1]. Although its definition had been a matter of debate [1], MetS is now a widely accepted concept [2], and has been used across multiple populations to assess cardiovascular and mortality risk [3]. For example, it was estimated that 11 million deaths world-wide can be attributed to MetS annually [3]. Although MetS has traditionally primarily been linked to CVD, studies suggest that MetS [4-7] and metabolic abnormalities more generally [7-9] may also be related to cognitive impairment as a type of organ dysfunction that burdens the global economy to extents similar to CVD [10]. Chronically elevated blood glucose levels, for instance, have consistently been associated with an increased risk of future cognitive impairment [11].

MetS [12] and its contributing parameters of metabolic dysfunction (e.g., [13]) are hugely prevalent in Western societies and on a global scale, but all are modifiable. This implies a potential for strategic improvement of public health that warrants clarification. We therefore examined associations of MetS, of each of its 5 components and of associated continuous parameters of metabolic dysfunction with cognitive impairment in a community-based sample of older adults without clinical dementia.

\section{Method}

\section{Study design}

We analyzed cross-sectional associations of MetS with cognitive impairment in the Biomarker Development for Postoperative Cognitive Impairment in the Elderly (BioCog) study (http://www.biocog.eu). The primary aim of the study is to identify biomarkers predictive of post-operative cognitive impairment in patients undergoing elective surgery at study sites in Utrecht, the Netherlands, and Berlin, Germany. Details on recruitment procedures and study protocol have been reported elsewhere [14] and the study was registered on 15th October 2014 at clinicaltrials.gov (NCT02265263). In brief, patients were eligible to participate if they were aged $\geq 65$ years, Caucasian, scheduled for elective surgery of any type with operative time $\geq 60 \mathrm{~min}$ and with an expected post-operative hospital treatment period of at least 7 days, and if they scored normal on a screening tool for dementia (Mini Mental State Examination, MMSE $\geq 24 / 30$ ). Of 7727 patients screened for inclusion, 933 were recruited between November 2014 and April
2017. Here, we report on baseline metabolic and cognitive data that were collected before surgery from the first 400 of those patients. Participants with missing data on any of the 5 MetS components or any missing cognitive data were excluded from our analysis.

\section{Clinical interview and physical examination}

Participants self-reported on smoking history and sociodemographic parameters. Arterial hypertension, diabetes, a history of transient ischemic attacks (TIA), a history of stroke and coronary heart disease (CHD) were ascertained from a combination of self-report and local hospital records on pre-existing conditions and medication. Weight and height were measured to calculate body mass index (BMI).

\section{Biomarker measurement}

Blood was collected immediately before induction of anesthesia in a supine position and following an overnight fast. HbA1c was measured in a laboratory adjacent to the respective hospital site. Blood was additionally centrifuged and serum samples stored at $-80^{\circ} \mathrm{C}$ for shipment to a central biobank repository. Samples were later retrieved from that biobank for measurement of glucose, TG and HDL-C levels. Those analyses were performed at a single laboratory. Because samples stored at the biobank were insufficient for $N=16$ participants of our analysis sample, data on glucose, TG and HDL-C were used from the immediate laboratory adjacent to the hospital site for those 16 participants. Sensitivity analyses revealed no influence of analysis laboratory on any of the results reported here (data not shown). For one participant, blood was collected after induction of anesthesia but before incision. Their data were not excluded.

\section{Definition of metabolic syndrome}

In accordance with standardized criteria [15], we used a slightly modified definition of MetS (Table 1). BMI was used to define obesity instead of waist circumference, since waist circumference was not measured in our study.

\section{Cognitive examination}

Participants underwent neuropsychological testing in a quiet hospital room usually on the day before surgery. The MMSE was used to screen for clinical dementia for inclusion into the study, before a series of computer-based (Cambridge Neuropsychological Test Automated Battery, CANTAB $^{\circ}$; Cambridge Cognition Ltd.) and paper-pencil tests were performed: Paired Associates Learning (PAL), Verbal Recognition Memory (VRM), Spatial Span (SSP), Simple Reaction Time (SRT), Trail-Making Test-B (TMT-B), and Grooved Pegboard (GP). Principal component analysis (PCA) with extraction of factors with 
Table 1 Definition of metabolic syndrome ${ }^{a}$

\begin{tabular}{|c|c|c|}
\hline Component & Standard criteria ${ }^{\mathrm{b}}$ & Criteria used in present study \\
\hline $\begin{array}{l}\text { Elevated waist } \\
\text { circumference }\end{array}$ & Population- and country-specific definitions & $\mathrm{BMI} \geq 30 \mathrm{~kg} / \mathrm{m}^{2}$ \\
\hline Elevated TG & $\mathrm{TG} \geq 150 \mathrm{mg} / \mathrm{dL}(1.7 \mathrm{mmol} / \mathrm{L})$, or drug treatment & Fasting TG $\geq 150 \mathrm{mg} / \mathrm{dl}(1.7 \mathrm{mmol} / \mathrm{L})$ \\
\hline Reduced HDL-C & $\begin{array}{l}\mathrm{HDL}-\mathrm{C}<40 \mathrm{mg} / \mathrm{dL}(1.0 \mathrm{mmol} / \mathrm{L}) \text { in males; } \mathrm{HDL}-\mathrm{C}<50 \mathrm{mg} / \mathrm{dl} \\
(1.3 \mathrm{mmol} / \mathrm{L}) \text { in females; or drug treatment }\end{array}$ & $\begin{array}{l}\mathrm{HDL}-\mathrm{C}<40 \mathrm{mg} / \mathrm{dl}(1.0 \mathrm{mmol} / \mathrm{L}) \text { in males } \\
\mathrm{HDL}-\mathrm{C}<50 \mathrm{mg} / \mathrm{dl}(1.3 \mathrm{mmol} / \mathrm{L}) \text { in females }\end{array}$ \\
\hline $\begin{array}{l}\text { Elevated } \\
\text { blood pressure }\end{array}$ & Systolic $\geq 130$ and/or diastolic $\geq 85 \mathrm{mmHg}$, or drug treatment & $\begin{array}{l}\text { Hypertension based on self-report and/or local } \\
\text { hospital records }\end{array}$ \\
\hline Elevated glucose & $\geq 100 \mathrm{mg} / \mathrm{dL}$ in plasma, or drug treatment & $\begin{array}{l}\text { 1. Fasting blood glucose } \geq 100 \mathrm{mg} / \mathrm{dL} \text { ( } 5.5 \mathrm{mmol} / \mathrm{L} \text { ) } \\
\text { (if not fasted, HbA1c } \geq 42 \mathrm{mmol} / \mathrm{mol}^{d} \text { ) } \\
\text { and/or } \\
\text { 2. Diabetes based on self-report and/or local hospital records }\end{array}$ \\
\hline
\end{tabular}

${ }^{a}$ The metabolic syndrome is defined as the presence of at least 3 of the 5 components

${ }^{\mathrm{b}}$ Consensus statement [15]

'Glucose measured in serum (nearly identical to plasma; [59])

${ }^{d}$ In the present sample, all participants were fasted

Eigenvalue $>1$ was applied to the 6 cognitive tests to derive a score of global cognitive ability (' $g$ ') [16]. $G$ is unaffected by test-specific measurement error, produces more reliable results compared with individual cognitive tests and typically accounts for around $40 \%$ of variance [17]. $G$ is independent of cognitive test battery [18], and all aforementioned tests have been used to calculate $g$ in the past (e.g., [18]). Visual inspection of a scree plot confirmed presence of a single factor (Eigenvalue 2.37) explaining $39.53 \%$ of variance in the data. Standardized residuals of that factor were saved to obtain an operant latent variable $g$ (factor loadings TMT-B, 0.77; PAL, 0.71; GP, 0.67; VRM, 0.56; SSP, 0.54; SRT, 0.49). 'Cognitive impairment' was defined as scoring in the lowest tertile of $g$ and was the outcome of interest in our analysis. As a screening tool for dementia [19], the MMSE was not used to calculate $g$.

\section{Statistical analysis}

Data for MMSE, TMT-B, SRT and GP were log transformed prior to analysis to approximate normal distribution. An initial univariate analysis of variance (ANOVA) compared MMSE scores across tertiles of $g$; a chi ${ }^{2}$ test compared associations of MMSE $<27$ (indicative of prodromal dementia) with presence of cognitive impairment.

Participants were divided into quartiles based on the respective distributions of HbAlc, glucose, TG, HDL-C and BMI. We then used multiple logistic regression to examine the association of each with odds of cognitive impairment using the lowest quartile as the reference category. In addition, we used each on a continuous scale. For each analysis, we ran three regression models: Model 1 was adjusted for age, sex and smoking. Model 2 included age, sex, smoking, BMI, TG, HDL-C, and either glucose or HbA1c. Model 3 additionally included CHD, TIA and stroke. To check for non-linearity in the association with cognitive impairment, we subsequently added quadratic terms into the respective final model (Model 3).

We next categorized MetS and each of its components based on established definitions (Table 1) and studied their association with odds of cognitive impairment using multiple logistic regression. Again, Model 1 was adjusted for age, sex and smoking, Model 2 included age, sex, smoking and all 5 MetS components, and Model 3 additionally controlled for CHD, TIA and stroke.

We then studied the association of the number of abnormal MetS components with the odds of cognitive impairment using 0 abnormal components as reference category. For the purpose of this analysis, the groups with 4 or 5 components were merged due to small participant numbers in these groups. Finally, the number of MetS components (range 0 to 5) was entered into a multiple logistic regression model. For these analyses, Model 1 controlled for age, sex and smoking, and Model 2 additionally controlled for CHD, TIA and stroke. All results remained unchanged following exclusion of 2 underweight participants $\left(\mathrm{BMI} \leq 18.5 \mathrm{~kg} / \mathrm{m}^{2}\right)$ and 1 participant with very high TG $(28.9 \mathrm{mmol} / \mathrm{L})$ in a separate analysis unless stated otherwise. SPSS version 18.0 (IBM Corporation, New York) was used.

\section{Results}

\section{Sample characteristics}

A total of 202 participants enrolled into the study had complete cognitive and MetS data. Demographic, metabolic and cognitive characterization of the analysis sample is shown in Table 2. Participants were most commonly scheduled for orthopedic, gynecologic/urologic or general surgery and a majority had elevated BP 
Table 2 Demographic, metabolic and cognitive sample characteristics

\begin{tabular}{|c|c|c|}
\hline & $\begin{array}{l}\text { Means } \pm S D \text {, median (interquartile range) } \\
\text { or } n \text { of total } N=202 \text { analysis sample }\end{array}$ & $\%$ of $\mathrm{N}$ \\
\hline \multicolumn{3}{|l|}{ Study site } \\
\hline UMC Utrecht, n (\%) & 33 & $16.3 \%$ \\
\hline Charité Berlin Campus Virchow, n (\%) & 114 & $56.4 \%$ \\
\hline Charité Berlin Campus Mitte, n (\%) & 55 & $27.2 \%$ \\
\hline Male, n (\%) & 121 & $59.9 \%$ \\
\hline Age, years, mean $\pm S D$ & $72.12 \pm 4.74$ & \\
\hline \multicolumn{3}{|l|}{ Smoking history, n (\%) } \\
\hline Missing & 28 & $13.9 \%$ \\
\hline Never smokers & 54 & $26.7 \%$ \\
\hline Former smokers & 93 & $46.0 \%$ \\
\hline Current smokers & 27 & $13.4 \%$ \\
\hline History of coronary heart disease, n (\%) & 28 & $13.9 \%$ \\
\hline History of stroke, n (\%) & 9 & $4.5 \%$ \\
\hline History of transient ischemic attack, n (\%) & 6 & $3.0 \%$ \\
\hline History of diabetes, n (\%) & 39 & $19.3 \%$ \\
\hline Non-insulin dependent diabetes, n (\%) & 23 & $11.4 \%$ \\
\hline Insulin-dependent diabetes, n (\%) & 16 & $7.9 \%$ \\
\hline History of dyslipidemia, n (\%) & 40 & $19.8 \%$ \\
\hline Body mass index $\left(\mathrm{BMl} ; \mathrm{kg} / \mathrm{m}^{2}\right)$, mean $\pm \mathrm{SD}$ & $27.12 \pm 4.39$ & \\
\hline Serum glucose (mmol/L), median (interquartile range) & $5.77(5.27-6.49)$ & \\
\hline $\mathrm{HbA} 1 \mathrm{c}^{\mathrm{a}}(\mathrm{mmol} / \mathrm{mol})$, mean $\pm \mathrm{SD}$ & $39.68 \pm 8.20$ & \\
\hline Triglycerides (TG) (mmol/L), median (interquartile range) & $1.31(1.04-1.79)$ & \\
\hline Total cholesterol ${ }^{a}(\mathrm{mmol} / \mathrm{L})$, mean $\pm \mathrm{SD}$ & $4.88 \pm 1.12$ & \\
\hline Low-density lipoprotein $^{\mathrm{a}}(\mathrm{LDL}-\mathrm{C})(\mathrm{mmol} / \mathrm{L})$, mean $\pm \mathrm{SD}$ & $3.11 \pm 0.98$ & \\
\hline High-density lipoprotein $(\mathrm{HDL}-\mathrm{C})(\mathrm{mmol} / \mathrm{L})$, mean $\pm \mathrm{SD}$ & $1.27 \pm 0.43$ & \\
\hline \multicolumn{3}{|l|}{ BMl categories, n (\%) } \\
\hline Underweight (BMI $\left.\leq 18.5 \mathrm{~kg} / \mathrm{m}^{2}\right), \mathrm{n}(\%)$ & 2 & $1.0 \%$ \\
\hline Normal/overweight (BMI 18.6-29.9kg/m²), n (\%) & 155 & $76.7 \%$ \\
\hline Obesity (BMI $\left.\geq 30 \mathrm{~kg} / \mathrm{m}^{2}\right), \mathrm{n}(\%)$ & 45 & $22.3 \%$ \\
\hline Elevated blood pressure ${ }^{\mathrm{b}}, \mathrm{n}(\%)$ & 123 & $60.9 \%$ \\
\hline Elevated fasting glucose ${ }^{\mathrm{b}}, \mathrm{n}(\%)$ & 125 & $61.9 \%$ \\
\hline Elevated $\mathrm{TG}^{\mathrm{b}}, \mathrm{n}(\%)$ & 60 & $29.7 \%$ \\
\hline Reduced HDL-C ${ }^{b}, \mathrm{n}(\%)$ & 69 & $34.2 \%$ \\
\hline Metabolic syndrome $\left(\right.$ MetS) ${ }^{b}, \mathrm{n}(\%)$ & 72 & $35.6 \%$ \\
\hline \multicolumn{3}{|l|}{ Number of MetS components ${ }^{\mathrm{b}}$} \\
\hline 0 & 27 & $13.4 \%$ \\
\hline 1 & 41 & $20.3 \%$ \\
\hline 2 & 62 & $30.7 \%$ \\
\hline 3 & 41 & $20.3 \%$ \\
\hline 4 & 21 & $10.4 \%$ \\
\hline 5 & 10 & $5.0 \%$ \\
\hline Factor of global ability $g$, mean \pm SD & $-0.06 \pm 1.01$ & \\
\hline Mini Mental State Examination (MMSE) ${ }^{a}$, median (interquartile range) & $29(28-30)$ & \\
\hline MMSE $<27^{\mathrm{a}}, \mathrm{n}(\%)$ & 12 & $6.0 \%$ \\
\hline
\end{tabular}

a for HbA1c, $N=155$; for total cholesterol, $N=158$; for LDL-C, $N=157$; for MMSE, $N=200$

${ }^{\mathrm{b}}$ for definition, see Table 1 
(60.9\%) and elevated fasting glucose $(61.9 \%)$ respectively (Table 1). Obesity was present in $22.3 \%$, TG were elevated in $29.7 \%$, and HDL-C was reduced in $34.2 \%$ of participants. Seventy-two participants (35.6\%) fulfilled the criteria for MetS.

\section{Comparison of Mini-Mental State Examination (MMSE) scores across tertiles of $\boldsymbol{g}$}

Scores on the MMSE differed statistically significantly across tertiles of $g\left(\mathrm{~F}(2,197)=12.38 ; p<0.001 ; \mathrm{np}^{2}=0.11\right)$. Participants with cognitive impairment (those scoring in the lowest tertile $g$ ) had lower MMSE (geometric mean 28.1, 95\% CI 27.8, 28.4) relative to the second (geometric mean 28.7, 95\% CI 28.4, 29.0) and third tertiles (geometric mean 29.1, 95\% CI 28.8, 29.4) (pairwise comparison range $p<0.001$ to $p=0.110$ ). Of 12 participants with MMSE $<27,8$ had cognitive impairment when defined from $g\left(\mathrm{chi}^{2}(1, N=200)=5.42 ; p=0.020\right)$.

\section{Age- and sex associations with cognitive impairment}

Age was directly associated with cognitive impairment. Each 5-year increase in age was associated with a 1.79-fold increased odds of impairment (OR 1.79 per 5-year increment, 95\% CI 1.30, 2.47; $p<0.001)$. Sex was unrelated to impairment in the same model (male versus female, OR $0.70,95 \%$ CI $0.38,1.28 ; p=0.25$ ).

\section{Continuous metabolic parameters and odds of cognitive impairment}

The odds of cognitive impairment according to each of the continuous metabolic parameters and their quartiles are shown in Table 3. HDL-C quartiles were significantly associated with cognitive impairment ( $p_{\text {trend }}$ across quartiles adjusted for age, sex, smoking $=0.004)$. Thus, persons in the highest versus lowest quartile of HDL-C had a 0.28 -fold odds (95\% CI 0.11-0.71). The association also survived addition of BMI, TG, glucose, CHD, TIA and stroke into the model ( $p_{\text {trend }}$ across quartiles $=$ 0.023). On a continuous scale, in the fully adjusted model, each 1 unit mmol/L higher HDL-C concentration was associated with a 0.39 -fold odds (OR 0.39; $95 \%$ CI $0.16,0.94 ; p=0.036$ ) of cognitive impairment.

Higher glucose levels were also related to a higher odds of cognitive impairment in the fully adjusted model $\left(p_{\text {trend }}\right.$ across quartiles $\left.=0.045\right)$. On a continuous scale, 1 $\mathrm{mmol} / \mathrm{L}$ higher glucose levels were associated with a statistically non-significant trend for a 1.21-fold odds (95\%-CI 0.97-1.51; $p=0.086)$ of cognitive impairment. BMI, TG levels, and HbA1c concentrations were not substantially related to cognitive impairment in these analyses. To test for non-linearity we added quadratic terms of the metabolic parameters to each of the fully adjusted models; however, none of these quadratic terms were statistically significant (HDL-C, $p=0.407$; TG, $p=$
0.556; BMI, $p=0.788$; glucose, $p=0.282$; HbA1c, $p=$ 0.849 ), suggesting that non-linear models did not improve model fit.

\section{Metabolic syndrome, the 5 MetS components and odds of cognitive impairment}

Participants with elevated TG were at 2.09-fold odds of cognitive impairment in analyses controlling for age, sex and smoking (OR 2.09, 95\% CI 1.08, 4.05, $p=0.028$ ) and when obesity, reduced HDL-C, elevated glucose and elevated $\mathrm{BP}$ were additionally adjusted for (OR 2.23, 95\% CI 1.07, 4.65, $p=0.033$; Table 4). Addition of CHD, TIA and stroke into the model led to statistically non-significant results, however (OR 1.86; 95\% CI 0.87, $4.00 ; p=0.110)$. Obesity, reduced HDL-C, elevated glucose and elevated BP were each not associated with cognitive impairment (all $p>0.05$; see Table 4). The presence of MetS was not significantly related to cognitive impairment (OR adjusted for age, sex, smoking 1.38; 95\% CI 0.74, 2.60; $p=0.310$; Table 4). The number of MetS components was also not significantly associated with impairment (OR per number of component increment, adjusted for age, sex, smoking, 1.16, 95\% CI 0.92, 1.45; $p=0.212$; Table 5). Pairwise comparison showed a lower odds of cognitive impairment in the group with $1 \mathrm{MetS}$ component compared with the reference group with 0 components in the fully adjusted model (OR 0.29; 95\% CI 0.09, 0.95; $p=0.041$ ) though no significant differences in the odds of cognitive impairment in participants with 2, 3 or 4/5 MetS components compared with the reference group were found (all $p>$ 0.05; Table 5).

\section{Discussion}

In this cross-sectional analysis of a sample of older surgical patients without clinical dementia, participants with lower HDL cholesterol (HDL-C) and those with elevated triglycerides (TG) were at increased likelihood of being cognitively impaired. Individuals with higher glucose levels also had a higher odds of cognitive impairment, although these results became apparent only in quartile analyses. Importantly, the associations for HDL-C and glucose, but not for elevated TG, were largely independent of one another, of other parameters of metabolic dysfunction, and of age, sex, smoking and a history of macrovascular disease. Obesity and elevated blood pressure were not substantially associated with cognitive impairment.

Associations of mid-life obesity [8], mid-life dyslipidemia $[20,21]$ and mid-life hypertension [22] with later cognitive impairment including increased risk of Alzheimer's disease and presence of Alzheimer's-type neuropathology [23, 24] are well-established. In later life, these risk factors are more difficult to evaluate partly due to an influence of 
Table 3 Odds of cognitive impairment according to continuous metabolic parameters

\begin{tabular}{|c|c|c|c|c|c|c|c|}
\hline & \multicolumn{4}{|l|}{ Quartiles } & \multirow[t]{2}{*}{$p_{\text {trend }}$} & \multicolumn{2}{|l|}{ Continuous parameters } \\
\hline & 1 & 2 & 3 & 4 & & OR $(95 \% \mathrm{Cl})$ per unit increment & $p$-value \\
\hline \multicolumn{8}{|l|}{ Body mass index } \\
\hline Cut-point $\left(\mathrm{kg} / \mathrm{m}^{2}\right)$ & $\leq 24.15$ & $24.16-26.70$ & $26.71-29.35$ & $\geq 29.36$ & & & \\
\hline $\begin{array}{l}\mathrm{n} \text { with cognitive } \\
\text { impairment / } \mathrm{N} \text { total }\end{array}$ & $19 / 51$ & $18 / 51$ & $18 / 50$ & $17 / 50$ & & & \\
\hline Model 1 OR (95\% Cl) & 1.00 (Reference) & $0.96(0.41,2.25)$ & $1.17(0.50,2.75)$ & $1.02(0.43,2.41)$ & 0.971 & $0.99(0.92,1.06)$ & 0.772 \\
\hline Model 2 OR (95\% Cl) & 1.00 (Reference) & $1.06(0.41,2.70)$ & $1.11(0.43,2.87)$ & $0.64(0.23,1.80)$ & 0.707 & $0.95(0.88,1.03)$ & 0.205 \\
\hline Model 3 OR (95\% Cl) & 1.00 (Reference) & $0.98(0.37,2.64)$ & $1.18(0.44,3.13)$ & $0.59(0.20,1.75)$ & 0.602 & $0.95(0.88,1.03)$ & 0.238 \\
\hline \multicolumn{8}{|l|}{ Triglycerides } \\
\hline Cut-point (mmol/L) & $\leq 1.04$ & $1.05-1.31$ & $1.32-1.79$ & $\geq 1.80$ & & & \\
\hline $\begin{array}{l}\mathrm{n} \text { with cognitive } \\
\text { impairment / } \mathrm{N} \text { total }\end{array}$ & $17 / 53$ & $14 / 49$ & $23 / 50$ & $18 / 50$ & & & \\
\hline Model 1 OR $(95 \% \text { Cl) })^{\mathrm{a}}$ & 1.00 (Reference) & $0.92(0.38,2.24)$ & $2.20(0.94,5.19)$ & $1.58(0.66,3.77)$ & 0.167 & $1.11(0.93,1.32)$ & 0.241 \\
\hline Model 2 OR $(95 \% \text { Cl) })^{\mathrm{a}}$ & 1.00 (Reference) & $1.07(0.39,2.91)$ & $2.22(0.82,5.98)$ & $0.91(0.31,2.73)$ & 0.259 & $1.02(0.88,1.18)$ & 0.835 \\
\hline Model 3 OR $(95 \%$ Cl) & 1.00 (Reference) & $1.08(0.38,3.07)$ & $2.08(0.75,5.76)$ & $0.73(0.23,2.31)$ & 0.237 & $1.02(0.88,1.18)$ & 0.791 \\
\hline \multicolumn{8}{|c|}{ High-density lipoprotein cholesterol } \\
\hline Cut-point (mmol/L) & $\leq 1.01$ & $1.02-1.27$ & $1.28-1.55$ & $\geq 1.56$ & & & \\
\hline $\begin{array}{l}\mathrm{n} \text { with cognitive } \\
\text { impairment / } \mathrm{N} \text { total }\end{array}$ & $28 / 54$ & $10 / 52$ & $21 / 52$ & $13 / 44$ & & & \\
\hline Model 1 OR (95\% Cl) & 1.00 (Reference) & $0.23(0.09,0.57)$ & $0.65(0.29,1.48)$ & $0.28(0.11,0.71)$ & 0.004 & $0.37(0.18,0.80)$ & 0.011 \\
\hline Model 2 OR (95\% Cl) & 1.00 (Reference) & $0.25(0.09,0.65)$ & $0.57(0.22,1.44)$ & $0.26(0.09,0.80)$ & 0.017 & $0.39(0.17,0.92)$ & 0.031 \\
\hline Model 3 OR (95\% Cl) & 1.00 (Reference) & $0.28(0.10,0.75)$ & $0.53(0.20,1.41)$ & $0.22(0.07,0.70)$ & 0.023 & $0.39(0.16,0.94)$ & 0.036 \\
\hline \multicolumn{8}{|l|}{ Glucose } \\
\hline Cut-point (mmol/L) & $\leq 5.27$ & $5.28-5.77$ & $5.78-6.49$ & $\geq 6.50$ & & & \\
\hline $\begin{array}{l}\mathrm{n} \text { with cognitive impairment } \\
/ \mathrm{N} \text { total }\end{array}$ & $21 / 54$ & $14 / 48$ & $14 / 52$ & $23 / 48$ & & & \\
\hline Model 1 OR (95\% Cl) & 1.00 (Reference) & $0.56(0.23,1.35)$ & $0.56(0.24,1.33)$ & $1.62(0.71,3.70)$ & 0.053 & $1.19(0.99,1.43)$ & 0.068 \\
\hline Model 2 OR (95\% Cl) & 1.00 (Reference) & $0.66(0.26,1.66)$ & $0.42(0.16,1.10)$ & $1.58(0.61,4.08)$ & 0.062 & $1.19(0.97,1.46)$ & 0.094 \\
\hline Model 3 OR (95\% Cl) & 1.00 (Reference) & $0.62(0.23,1.66)$ & $0.45(0.16,1.21)$ & $1.84(0.69,4.91)$ & 0.045 & $1.21(0.97,1.51)$ & 0.086 \\
\hline \multicolumn{8}{|l|}{$\mathrm{HbA} 1 \mathrm{c}$} \\
\hline Cut-point (mmol/mol) & $\leq 35.5$ & $35.6-38.8$ & $38.9-42.1$ & $\geq 42.2$ & & & \\
\hline $\begin{array}{l}\mathrm{n} \text { with cognitive } \\
\text { impairment / } \mathrm{N} \text { total }\end{array}$ & $15 / 46$ & $14 / 37$ & $12 / 38$ & $17 / 34$ & & & \\
\hline Model 1 OR (95\% Cl) & 1.00 (Reference) & $1.26(0.49,3.27)$ & $0.65(0.24,1.75)$ & $2.15(0.83,5.54)$ & 0.142 & $1.03(0.99,1.08)$ & 0.137 \\
\hline Model 2 OR (95\% Cl) & 1.00 (Reference) & $1.24(0.44,3.46)$ & $0.54(0.18,1.63)$ & $1.71(0.61,4.80)$ & 0.235 & $1.03(0.99,1.08)^{b}$ & 0.137 \\
\hline Model 3 OR (95\% Cl) & 1.00 (Reference) & $0.75(0.24,2.39)$ & $0.55(0.18,1.73)$ & $1.47(0.49,4.36)$ & 0.420 & $1.04(0.99,1.09)^{b}$ & 0.115 \\
\hline
\end{tabular}

Results shown for logistic regression analyses with outcome cognitive impairment. $p$-value for trend (2-sided) based on the respective median within quartiles, used as a continuous variable, and analyzed using the Wald chi $^{2}$ statistic. $\mathrm{Cl}$, confidence interval; OR, odds ratio

a results largely unchanged following exclusion of $N=1$ outlier with high TG levels $(28.9 \mathrm{mmol} / \mathrm{L})$

${ }^{b}$ in these models, HDL-C was significantly associated with cognitive impairment (Model 2: OR 0.27, $95 \% \mathrm{Cl} 0.09,0.79, p=0.016 ;$ Model 3: OR $0.28,95 \% \mathrm{Cl} 0.09$,

$0.83, p=0.022 ;$ for TG and BMI, all $p>0.05$ in these models)

Model 1: adjusted for age, sex, smoking

Model 2: Model $1+$ TG quartiles, HDL-C quartiles, BMI quartiles, glucose quartiles (for quartile analyses) or Model $1+\mathrm{TG}, \mathrm{HDL}-\mathrm{C}$, BMI and glucose (for continuous parameters) (analysis $N=202$ ), or for HbA1c: Model $1+\mathrm{TG}$ quartiles, HDL-C quartiles, BMI quartiles (for HbA1c quartile analyses) or Model $1+\mathrm{TG}, \mathrm{HDL}-\mathrm{C}$ and BMI (for analysis of $\mathrm{HbA1c}$ as continuous parameter) (analysis $N=155$ )

Model 3: Model $2+$ CHD, TIA, stroke

frailty [25], and previous studies of dyslipidemia in older age and cognitive impairment have produced mixed results. Null findings for diagnosed dyslipidemia [26] and for levels of total cholesterol [9], HDL-C [27] and TG [27, 28] are contrasted with studies showing an increased risk of cognitive impairment in people with low HDL-C $[29,30]$ or elevated TG in later life [31,32]. Here, our data suggest a contribution of low HDL-C to cognitive impairment that 
Table 4 MetS, each of the 5 MetS components and odds of cognitive impairment

\begin{tabular}{|c|c|c|c|c|c|c|}
\hline & \multicolumn{2}{|l|}{ Model 1} & \multicolumn{2}{|l|}{ Model 2} & \multicolumn{2}{|l|}{ Model 3} \\
\hline & OR $(95 \% \mathrm{Cl})$ & $p$ & OR $(95 \% \mathrm{Cl})$ & $p$ & OR $(95 \% \mathrm{Cl})$ & $p$ \\
\hline Metabolic syndrome & $1.38(0.74,2.60)$ & 0.310 & - & - & $1.25(0.65,2.42)$ & 0.503 \\
\hline Obesity & $1.07(0.52,2.23)$ & 0.852 & $1.00(0.46,2.17)$ & 0.997 & $1.08(0.48,2.43)$ & 0.845 \\
\hline Elevated triglycerides & $2.09(1.08,4.05)$ & 0.028 & $2.23(1.07,4.65)$ & 0.033 & $1.86(0.87,4.00)$ & 0.110 \\
\hline Reduced high-density lipoprotein & $1.19(0.63,2.23)$ & 0.600 & $0.86(0.42,1.77)$ & 0.691 & $0.87(0.41,1.82)$ & 0.704 \\
\hline Elevated blood pressure & $1.11(0.60,2.07)$ & 0.740 & $1.04(0.54,2.00)$ & 0.911 & $0.86(0.44,1.71)$ & 0.668 \\
\hline Elevated glucose & $1.12(0.60,2.08)$ & 0.721 & $0.98(0.51,1.88)$ & 0.948 & $1.09(0.55,2.14)$ & 0.811 \\
\hline
\end{tabular}

Results shown for logistic regression analyses for odds of cognitive impairment. $\mathrm{Cl}$, confidence interval; OR, odds ratio. For definitions of metabolic syndrome components, see Table 1. Model 1: separate models associated each exposure variable with cognitive impairment with adjustment for age, sex and smoking ( $N=202)$. Model 2: single model including age, sex, smoking, obesity, elevated TG, reduced HDL-C, elevated blood pressure, elevated glucose ( $N=202)$. Model 3: single model including age, sex, smoking, obesity, elevated TG, reduced HDL-C, elevated blood pressure, elevated glucose, CHD, TIA, stroke (N=200). Model 3 is a separate model for MetS. Results largely unchanged following exclusion of $N=1$ outlier with high TG levels $(28.9 \mathrm{mmol} / \mathrm{L})$

could indicate a causal relationship. Indeed, $\mathrm{HDL}-\mathrm{C}$ has vasoprotective and anti-inflammatory properties [33] so that reduced inflammation could be a plausible mediator of the association in our sample. TG levels correlate with atherogenic and pro-inflammatory triglyceride-rich lipoproteins (TRL) [34] which may directly promote cognitive impairment. Our findings also suggest a contribution of macrovascular disease to the association of elevated TG with cognitive impairment. Cerebrovascular disease could be a mediator in the relationship, for instance. We are unable to determine this from the present study. Nonetheless, irrespective of the issue of causality and mediatory processes, elevated TG and HDL-C both appear to be useful risk markers with potential for utility in clinical settings and could contribute to screening tool development.

The disparate findings on HDL-C as a continuous metabolic parameter versus the dichotomized MetS component 'reduced HDL-C' suggest that the latter at-risk group may not necessarily be well-captured by the standardized, sex-specific cut-off points that are currently in use [15]. Their reevaluation and update, including determination whether sex-specific cut-offs are necessary, may be warranted. We found no significant association when we used TG as a continuous variable or as quartiles in our analysis. In contrast, when based on the standardized cut-off point [15], elevated TG were significantly associated with cognitive impairment at least in largely unadjusted analyses, suggesting that this threshold is appropriate for cognitive risk prediction. Nevertheless, given the relatively small sample size, the results of our analysis need to be interpreted cautiously and require replication in larger samples.

Previous epidemiological research has consistently implicated hyperglycemia as detrimental to cognition. Irrespective of whether measured at midlife or later life, diabetes, pre-diabetes [35-37], and poorer glycemic control in people with diabetes [37] have been linked to increased risk of vascular-type impairment as well as Alzheimer's disease [38]. Neurotoxic effects of glucose on the brain [39] and hyperglycemia-induced vascular damage [40] which appear to generate vascular impairment as well as facilitate neurodegeneration characteristic of Alzheimer's disease [41] have been suggested as underlying the relationship. In our sample, we found evidence for a more complex role of glucose in cognitive impairment that became apparent only in quartile analyses and was not supported by analyses of HbA1c as an index of long-term glycemic control. The marginally significant result could thus reflect Type I error. The fact

Table 5 Number of MetS components and odds of cognitive impairment

\begin{tabular}{|c|c|c|c|c|}
\hline \multirow[t]{2}{*}{ Number of components } & \multicolumn{2}{|l|}{ Model 1} & \multicolumn{2}{|l|}{ Model 2} \\
\hline & OR $(95 \% \mathrm{Cl})$ & $p$ & OR $(95 \% \mathrm{Cl})$ & $p$ \\
\hline 0 & 1.00 (Reference) $^{a}$ & - & 1.00 (Reference) $^{\mathrm{b}}$ & - \\
\hline 1 & $0.36(0.11,1.15)^{a}$ & 0.084 & $0.29(0.09,0.95)^{b}$ & 0.041 \\
\hline 2 & $1.02(0.38,2.77)^{\mathrm{a}}$ & 0.965 & $0.93(0.34,2.52)^{b}$ & 0.878 \\
\hline 3 & $0.94(0.32,2.77)^{\mathrm{a}}$ & 0.902 & $0.76(0.26,2.28)^{b}$ & 0.629 \\
\hline $4 / 5^{c}$ & $1.23(0.40,3.77)^{\mathrm{a}}$ & 0.713 & $0.99(0.31,3.12)^{b}$ & 0.982 \\
\hline Number of components (continuous) ${ }^{d}$ & $1.16(0.92,1.45)$ & 0.212 & $1.11(0.88,1.41)$ & 0.387 \\
\hline
\end{tabular}

Model 1: adjusted for age, sex and smoking $(N=202)$. Model 2: adjusted for age, sex, smoking, CHD, TIA, stroke $(N=200)$

${ }^{\mathrm{a}}$ single model; ${ }^{\mathrm{b}}$ single model

'due to small $\mathrm{N}$ in each, groups with 4 or 5 components were merged in this analysis

drange 0 to 5 
that - for consistency with standard definitions of MetS [15] - diagnosis of diabetes qualified for inclusion in the 'elevated glucose' group, may also have 'diluted' that group leading to non-significant results. Alternatively, the standardized cut-off point for 'elevated glucose' [15] may not be appropriate for our sample of surgical patients who may have had extended periods of fasting prior to blood collection or for whom fasting status may not have been recorded with sufficient rigor. The high prevalence of 'elevated glucose' (61.9\%, albeit as aforementioned this included participants with diabetes) supports the latter possibility. The precise role of glucose in cognitive impairment thus remains to be explored further.

The evidence for obesity in older age as a risk factor for cognitive impairment is limited [8] with occasional implication of overweight, obesity and elevated waist circumference as protective factors [29, 42, 43]. Here, obesity and BMI both were not related to cognition. At the lower end of the body weight spectrum, the relationship may be affected by frailty [25] but results on obesity and BMI did not change when underweight participants were excluded from our analysis or when quadratic terms were added into the model. Elevated blood pressure, too, was unrelated to cognitive impairment contrasting with some other cross-sectional and longitudinal studies of older adults [22].

Previous studies of the MetS construct and cognitive impairment have occasionally produced null results similar to our own [44, 45]. However, others did report associations with impairment [7, 29, 30, 46, 47]. For instance, in the Singapore Longitudinal Ageing Study, participants with MetS were at 1.46 -fold increased risk of mild cognitive impairment (MCI) during 6-year follow-up [7]. In the French Three-City Study of more than 7000 older adults, MetS - in line with its status as a vascular risk factor - was selectively associated with a 2.42-fold increased risk of impairment of vascular origin [29]. Finally, women with MetS were at 2.47-fold increased risk of poor memory 12 years later in a Finnish investigation [30] and a pooled analysis of three studies reported that MetS was overall associated with 2.95-fold increased risk of progression from $\mathrm{MCI}$ to dementia [48]. The Finnish study [30] and some others [49] additionally reported a linear relationship of the number of MetS components with cognitive risk, but we and others $[29,47]$ found no such evidence. Disparity of our results from previous studies could stem from our slightly modified definition of MetS, the cross-sectional study design, the surgical nature of our sample, and the high prevalence of MetS (35.6\%) compared with those studies (12.9\% [30]; $15.8 \%$ [29]; $22.4 \%$ [7]) but is in line with a recent systematic review of 25 studies which concluded that the evidence on associations of MetS with cognitive impairment in older age is insufficient at present [49]. A recent report of accumulation of beta amyloid in the brains of people with MetS [50] demonstrate the need for further research into the cognitive and neuropathological consequences of the syndrome.

Each MetS component (except obesity) can be modified through pharmaceutical treatment and the potential benefit of concurrent tackling of several components is being increasingly recognized. Thus, the ACCORD-MIND trial recently tested the effect of antidiabetic, lipid lowering and blood pressure lowering therapy, in a double $2 \times 2$ factorial design; however, neither improved glycemic control [51], nor improved lipid levels or blood pressure [52] affected the rate of cognitive decline during 40-month follow-up, suggesting that the epidemiological evidence linking elevated glucose, dyslipidemia and elevated blood pressure to cognitive impairment may be confounded. Further similarly complex trials are needed for clarification of the effects of strategic targeting of different metabolic parameters, as well as benefits of concurrent treatment, on cognitive risk.

Strengths of our study include a multi-center design and the use of a comprehensive cognitive test battery that was validated through comparison with an instrument commonly used to assess cognitive status. Consideration of several metabolic parameters in a single analysis was able to evaluate relative independence of each from one another in their relationship with cognition. Thus far the $5 \mathrm{MetS}$ components have mainly been investigated in isolation. Only a few studies directly compared the components in terms of their association with cognitive risk and had implicated low HDL-C [30], elevated TG [29], hypertension [46] and, most frequently, hyperglycemia $[26,44]$ as independent risk markers. However, some limitations need to be considered. Surgical patients are at risk of developing post-operative cognitive impairment [53] and so are of special interest in terms of their cognitive status. To our knowledge the present study is the first to assess MetS and cognitive impairment in this type of sample. At the same time, the focus on surgical patients as well as self-selection bias preventing unwell patients to enroll limits the generalizability of our findings to the general population that includes healthy, community-dwelling individuals. Further, we used BMI as a proxy for central obesity [12] though strictly speaking central obesity can only be determined through direct measurement. We also did not consider MetS-related complications such as retinopathy in our analysis. The possibility of confounding of our statistically significant findings by unmeasured factors such as diet or physical activity, too, remains. Because 'cognitive impairment' was defined from a cognitive summary score, our results are not 
necessarily comparable to studies that used standardized constructs such as MCI. Due to the cross-sectional study design we were unable to evaluate participants' metabolic function during the decades prior to enrolment and did not consider anti-hyperglycemic, anti-hypertensive and lipid-lowering treatment in our analysis. Associations of elevated blood pressure with cognitive impairment may thus have become apparent had we controlled for or stratified by treatment. We deem confounding of our findings on HDL-C by anti-dyslipidemia drugs unlikely given the balance of epidemiological and trial evidence which suggests a limited role of drugs such as statins or fibrates in cognitive decline [54-56]. In any event, the fact that we observed associations of HDL-C with cognitive impairment despite lacking data on treatment indicates that the underlying processes may be mechanistic and dose-dependent on lipid concentrations irrespective of whether they are treated. Finally, our sample was relatively small and so the fact that we did not find significant associations for some of the MetS components does not rule out that studies with larger sample size may be able to detect smaller effects. Further prospective, epidemiological studies comparing the contributions of each of the 5 components to cognitive risk are needed and should take advantage of a range of different types of samples to gain a full understanding of any sample-specific relationships of MetS with cognitive impairment. Researchers should additionally consider analysis of inflammatory markers, which may interact with MetS in determining cognitive outcome [57], as well as pre-morbid cognitive ability (which affects both cognitive ability and metabolic risk in older age [58]) to explore mediation and confounding.

In conclusion, in this cross-sectional analysis of older adults who were all free of clinical dementia and scheduled to undergo surgery, lower HDL-C and elevated TG were each associated with presence of cognitive impairment defined as reduced cognitive performance relative to the total sample. For HDL-C, but not for elevated TG, the finding was independent of age, sex, smoking, the remaining parameters of metabolic dysfunction, as well as of macrovascular disease. This suggests potential for a causal relationship. The MetS construct per se was not associated with cognition. Prospective studies should compare the cognitive risk associated with different parameters of metabolic dysfunction in view to identify at-risk individuals and to shed light on underlying pathophysiological mechanisms considering that the evidence for metabolic parameters as effective targets for intervention is currently limited.

\section{Abbreviations}

BMI: Body mass index; BP: Blood pressure; CHD: Coronary heart disease; HbA1c: Glycated hemoglobin; HDL-C: High-density lipoprotein cholesterol; LDL-C: Low-density lipoprotein cholesterol; MCl: Mild cognitive impairment; MetS: Metabolic syndrome; TG: Triglycerides; TIA: Transient ischemic attack

\section{Funding}

The BioCog study was funded by the European Union, Seventh Framework Programme [FP7/2007-2013], under grant agreement no. HEALTH-F2-2014-602461 BioCog (Biomarker Development for Postoperative Cognitive Impairment in the Elderly): http://www.biocog.eu. The funding body had no role in the design of the study, data collection, analysis and interpretation of data, and in writing the manuscript.

\section{Availability of data and materials}

The datasets generated and/or analyzed during the current study are not publicly available due to threats to subject privacy but are available from the corresponding author on reasonable request.

\section{Authors' contributions}

Study concept and design: AS, GW, CS, TP. Data collection: DH, JJ, IF. Statistical analysis and interpretation: IF. Drafting of initial manuscript: TP, IF. Review of manuscript for critical intellectual content: IF, JJ, DH, AS, GW, CS, TP. All authors read and approved the final manuscript.

\section{Ethics approval and consent to participate}

The study was conducted in compliance with the Declaration of Helsinki. All participants gave written informed consent. The study protocol was approved by the institutional ethics review boards (Ethikkommission, Ethikausschuss 2 am Campus Virchow-Klinikum, Charité Universitatsmedizin Berlin, Reference EA2/092/14; Medisch Ethische Toetsingscommissie, UMC Utrecht, Reference 14/469).

\section{Consent for publication}

Not applicable.

\section{Competing interests}

GW is coordinator of the BioCog consortium and is chief executive of the company Pharmaimage Biomarker Solutions GmbH (http://www.pipharmaimage.com). Among other academic and private partners, the company is a partner of the BioCog study. CS and TP are project leaders in BioCog. CS, TP, AS, JJ, DH and IF declare that they have no conflicts of interest related to this article.

\section{Publisher's Note}

Springer Nature remains neutral with regard to jurisdictional claims in published maps and institutional affiliations.

\section{Author details}

${ }^{1}$ Molecular Epidemiology Research Group, Max-Delbrueck-Center for Molecular Medicine in the Helmholtz Association (MDC), Berlin, Germany. ${ }^{2}$ Charité - Universitaetsmedizin Berlin, corporate member of Freie Universitaet Berlin, Humboldt-Universitaet zu Berlin, and Berlin Institute of Health $(\mathrm{BIH})$, Berlin, Germany. ${ }^{3}$ University Medical Center Utrecht, Utrecht, the Netherlands. ${ }^{4} \mathrm{MDC} / \mathrm{BIH}$ Biobank, Max-Delbrueck-Center for Molecular Medicine in the Helmholtz Association (MDC), and Berlin Institute of Health $(\mathrm{B} \mid \mathrm{H})$, Berlin, Germany.

Received: 7 September 2018 Accepted: 18 February 2019 Published online: 07 March 2019

\section{References}

1. Shin JA, Lee JH, Lim SY, Ha HS, Kwon HS, Park YM, et al. Metabolic syndrome as a predictor of type 2 diabetes, and its clinical interpretations and usefulness. J Diabetes Investig. 2013;4(4):334-43.

2. Eckel RH, Alberti KG, Grundy SM, Zimmet PZ. The metabolic syndrome. Lancet. 2010;375(9710):181-3.

3. The Global Burden of Metabolic Risk Factors for Chronic Diseases Collaboration. Cardiovascular disease, chronic kidney disease, and diabetes mortality burden of cardiometabolic risk factors from 1980 to 2010: a comparative risk assessment. Lancet Diabetes Endocrinol. 2014;2(8):634-47.

4. Chen B, Jin X, Guo R, Chen Z, Hou X, Gao F, et al. Metabolic syndrome and cognitive performance among Chinese $>/=50$ years: a cross-sectional study with 3988 participants. Metab Syndr Relat Disord. 2016;14(4):222-7.

5. Exalto LG, van der Flier WM, van Boheemen CJ, Kappelle LJ, Vrenken H, Teunissen $C$, et al. The metabolic syndrome in a memory clinic population: relation with clinical profile and prognosis. J Neurol Sci. 2015;351(1-2):18-23. 
6. Rouch I, Trombert B, Kossowsky MP, Laurent B, Celle S, Ntougou Assoumou $\mathrm{G}$, et al. Metabolic syndrome is associated with poor memory and executive performance in elderly community residents: the PROOF study. Am J Geriatr Psychiatry. 2014:22(11):1096-104.

7. Ng TP, Feng L, Nyunt MS, Feng L, Gao Q, Lim ML, et al. Metabolic syndrome and the risk of mild cognitive impairment and progression to dementia: follow-up of the Singapore longitudinal ageing study cohort. JAMA Neurol. 2016:73(4):456-63.

8. Pedditizi E, Peters R, Beckett N. The risk of overweight/obesity in mid-life and late life for the development of dementia: a systematic review and meta-analysis of longitudinal studies. Age Ageing. 2016;45(1):14-21.

9. Okusaga O, Stewart MC, Butcher I, Deary I, Fowkes FG, Price JF. Smoking, hypercholesterolaemia and hypertension as risk factors for cognitive impairment in older adults. Age Ageing. 2013;42(3):306-11.

10. Abbott A. Dementia: a problem for our age. Nature. 2011;475(7355):S2-4.

11. Geijselaers SL, Sep SJS, Stehouwer CDA, Biessels GJ. Glucose regulation, cognition, and brain MRI in type 2 diabetes: a systematic review. Lancet Diabetes Endocrinol. 2015;3:75-89.

12. Ford ES. Prevalence of the metabolic syndrome defined by the International Diabetes Federation among adults in the U.S. Diabetes Care. 2005:28:2745-9.

13. McDonald M, Hertz RP, Unger AN, Lustik MB. Prevalence, awareness, and management of hypertension, dyslipidemia, and diabetes among United States adults aged 65 and older. J Gerontol A Biol Sci Med Sci. 2009;64(2): 256-63.

14. Winterer G, Androsova G, Bender O, Boraschi D, Borchers F, Dschietzig TB, et al. Personalized risk prediction of postoperative cognitive impairment rationale for the EU-funded BioCog project. Eur Psychiatry. 2018;50:34-39.

15. Alberti KGMM, Eckel RH, Grundy SM, Zimmet PZ, Cleeman Jl, Donato KA, et al. Harmonizing the metabolic syndrome. A joint interim statement of the International Diabetes Federation Task Force on Epidemiology and Prevention; National Heart, Lung, and Blood Institute; American Heart Association; World Heart Federation; International Atherosclerosis Society; and International Association for the Study of Obesity. Circulation. 2009;120:1640-545.

16. Spearman C. 'General intelligence', objectively determined and measured. Am J Psychol. 1904;15:201-92.

17. Deary IJ, Penke L, Johnson W. The neuroscience of human intelligence differences. Nat Rev Neurosci. 2010;11:201-11.

18. Johnson W, Nijenhuis J, Bouchard TJ Jr. Still just $1 \mathrm{~g}$ : consistent results from five test batteries. Intelligence. 2008;36(1):81-95.

19. O'Connor DW, Pollitt PA, Hyde JB, Fellows JL, Miller ND, Brook CP, et al. The reliability and validity of the Mini-Mental State in a British community survey. J Psychiatr Res. 1989;23:87-96.

20. Bruce DG, Davis WA, Davis TME. Low serum HDL-cholesterol concentrations in mid-life predict late-life cognitive impairment in type 2 diabetes: the Fremantle Diabetes Study. J Diabetes Complicat. 2017;31:945-947

21. Power MC, Rawlings A, Sharrett AR, Bandeen-Roche K, Coresh J, Ballantyne CM, et al. Association of midlife lipids with 20-year cognitive change: a cohort study. Alzheimers Dement. 2018;14:167-177.

22. Van den Berg E, Kloppenborg RP, Kessels RPC, Kappelle LJ, Biessels GJ. Type 2 diabetes mellitus, hypertension, dyslipidemia and obesity: a systematic comparison of their impact on cognition. Biochim Biophys Acta. 2009;1792:470-81.

23. Nagga K, Gustavsson AM, Stomrud E, Lindqvist D, van Westen D, Blennow $\mathrm{K}$, et al. Increased midlife triglycerides predict brain beta-amyloid and tau pathology 20 years later. Neurology. 2018;90(1):e73-81.

24. Xu WL, Atti AR, Gatz M, Pedersen NL, Johansson B, Fratiglioni L. Midlife overweight and obesity increase late-life dementia risk: a population-based twin study. Neurology. 2011;76(18):1568-74.

25. Strandberg TE, Stenholm S, Strandberg AY, Salomaa W, Pitkala KH, Tilvis RS. The "obesity paradox," frailty, disability, and mortality in older men: a prospective, longitudinal cohort study. Am J Epidemiol. 2013;178(9):1452-60.

26. Fan YC, Hsu JL, Tung HY, Chou CC, Bai CH. Increased dementia risk predominantly in diabetes mellitus rather than in hypertension or hyperlipidemia: a population-based cohort study. Alzheimers Res Ther. 2017;9(1):7.

27. Yaffe K, Haan M, Blackwell T, Cherkasova E, Whitmer RA, West N. Metabolic syndrome and cognitive decline in elderly Latinos: findings from the Sacramento Area Latino Study of Aging study. J Am Geriatr Soc. 2007;55(5):758-62.

28. Orengo CA, Kunik ME, Molinari VA, Teasdale TA, Workman RH, Yudofsky SC. Association of serum cholesterol and triglyceride levels with agitation and cognitive function in a geropsychiatry unit. J Geriatr Psychiatry Neurol. 1996;9:53-6.
29. Raffaitin C, Gin H, Empana JP, Helmer C, Berr C, Tzourio C, et al. Metabolic syndrome and risk for incident Alzheimer's disease or vascular dementia: the Three-City Study. Diabetes Care. 2009;32(1):169-74.

30. Komulainen P, Lakka TA, Kivipelto M, Hassinen M, Helkala EL, Haapala I, et al Metabolic syndrome and cognitive function: a population-based follow-up study in elderly women. Dement Geriatr Cogn Disord. 2007;23(1):29-34.

31. Shao TN, Yin GZ, Yin XL, Wu JQ, Du XD, Zhu HL, et al. Elevated triglyceride levels are associated with cognitive impairments among patients with major depressive disorder. Compr Psychiatry. 2017;75:103-9.

32. Corley J, Starr JM, Deary IJ. Serum cholesterol and cognitive functions: the Lothian Birth Cohort 1936. Int Psychogeriatr. 2015;27(3):439-53.

33. Luscher TF, Landmesser U, von Eckardstein A, Fogelman AM. High-density lipoprotein: vascular protective effects, dysfunction, and potential as therapeutic target. Circ Res. 2014;114(1):171-82.

34. Talayero BG, Sacks FM. The role of triglycerides in atherosclerosis. Curr Cardiol Rep. 2011;13(6):544-52.

35. Roriz-Filho SJ, Sa-Roriz TM, Rosset I, Camozzato AL, Santos AC, Chaves ML, et al. (Pre)diabetes, brain aging, and cognition. Biochim Biophys Acta. 2009; 1792(5):432-43.

36. Lu FP, Lin K-P, Kuo H-K. Diabetes and the risk of multi-system aging phenotypes: a systematic review and meta-analysis. PLoS One. 2009;4:e4144.

37. Tuligenga RH, Dugravot A, Tabak AG, Elbaz A, Brunner EJ, Kivimaki M, et al. Midlife type 2 diabetes and poor glycaemic control as risk factors for cognitive decline in early old age: a post-hoc analysis of the Whitehall II cohort study. Lancet Diabetes Endocrinol. 2014;2(3):228-35.

38. Strachan MWJ, Reynolds RM, Frier BM, Mitchell RJ, Price JF. The relationship between type 2 diabetes and dementia. Br Med Bull. 2008;88:131-46.

39. Tomlinson DR, Gardiner NJ. Glucose neurotoxicity. Nat Rev Neurosci. 2008; 9(1):36-45.

40. Biessels GJ, Strachan MW, Visseren FL, Kappelle L, Whitmer RA. Dementia and cognitive decline in type 2 diabetes and prediabetic stages: towards targeted interventions. Lancet Diabetes Endocrinol. 2014;2(3):246-55.

41. Attems J, Jellinger KA. The overlap between vascular disease and Alzheimer's disease--lessons from pathology. BMC Med. 2014;12:206.

42. Sturman MT, Mendes de Leon CF, Bienias JL, Morris MC, Wilson RS, Evans DA. Body mass index and cognitive decline in a biracial community population. Neurology. 2008;70:360-7.

43. Thilers PP, Macdonald SW, Nilsson LG, Herlitz A. Accelerated postmenopausal cognitive decline is restricted to women with normal BMI: longitudinal evidence from the Betula project. Psychoneuroendocrinology. 2010;35:516-24.

44. Overman MJ, Pendleton N, O'Neill TW, Bartfai G, Casanueva FF, Forti G, et al. Glycemia but not the metabolic syndrome is associated with cognitive decline: findings from the European Male Ageing Study. Am J Geriatr Psychiatry. 2017;25(6):662-71

45. Roberts RO, Geda YE, Knopman DS, Cha RH, Boeve BF, Ivnik RJ, et al. Metabolic syndrome, inflammation, and nonamnestic mild cognitive impairment in older persons: a population-based study. Alzheimer Dis Assoc Disord. 2010;24(1):11-8.

46. Levin BE, Llabre MM, Dong C, Elkind MS, Stern Y, Rundek T, et al. Modeling metabolic syndrome and its association with cognition: the Northern Manhattan study. J Int Neuropsychol Soc. 2014;20(10):951-60.

47. Yaffe K, Kanaya A, Lindquist K, Simonsick EM, Harris T, Shorr Rl, et al. The metabolic syndrome, inflammation, and risk of cognitive decline. J Am Med Assoc. 2004:292:2237-42

48. Pal K, Mukadam N, Petersen I, Cooper C. Mild cognitive impairment and progression to dementia in people with diabetes, prediabetes and metabolic syndrome: a systematic review and meta-analysis. Soc Psychiatry Psychiatr Epidemiol. 2018;53(11):1149-60.

49. Assuncao N, Sudo FK, Drummond C, de Felice FG, Mattos P. Metabolic syndrome and cognitive decline in the elderly: a systematic review. PLoS One. 2018;13(3):e0194990.

50. Gomez G, Beason-Held LL, Bilgel M, An Y, Wong DF, Studenski S, et al. Metabolic syndrome and amyloid accumulation in the aging brain. J Alzheimers Dis. 2018;65(2):629-39.

51. Launer LJ, Miller ME, Williamson JD, Lazar RM, Gerstein HC, Murray AM, et al. Effects of intensive glucose lowering on brain structure and function in people with type 2 diabtes (ACCORD MIND): a randomised open-label substudy. Lancet Neurol. 2011;10:969-77.

52. Williamson JD, Launer LJ, Bryan RN, Coker LH, Lazar RM, Gerstein HC, et al. Cognitive function and brain structure in persons with type 2 diabetes 
mellitus after intensive lowering of blood pressure and lipid levels: a randomized clinical trial. JAMA Intern Med. 2014;174(3):324-33.

53. Rundshagen I. Postoperative cognitive dysfunction. Dtsch Arztebl Int. 2014; 111(8):119-25.

54. Ancelin ML, Carriere I, Barberger-Gateau P, Auriacombe S, Rouaud O, Fourlanos S, et al. Lipid lowering agents, cognitive decline, and dementia: the three-city study. J Alzheimers Dis. 2012;30(3):629-37.

55. McGuinness B, Craig D, Bullock R, Passmore P. Statins for the prevention of dementia. The Cochrane Database Syst Rev. 2016;(1):Cd003160. PubMed ID: 26727124.

56. Zimering MB, Knight J, Ge L, Bahn G. Predictors of cognitive decline in older adult type 2 diabetes from the veterans affairs diabetes trial. Front Endocrinol. 2016;7:123.

57. Dik MG, Jonker C, Comijis HC, Deeg DJ, Kok A, Yaffe K et al. Contribution of metabolic syndrome components to cognition in older individuals. Diabetes Care. 2007;30(10): 2655-60

58. Altschul DM, Starr J, Deary IJ. Cognitive function in early and later life is associated with blood glucose in older individuals: analysis of the Lothian Birth Cohort of 1936. Diabetologia. 2018;61:1946-55.

59. Frank EA, Shubha MC, D'Souza CJ. Blood glucose determination: plasma or serum? J Clin Lab Anal. 2012;26(5):317-20.

Ready to submit your research? Choose BMC and benefit from:

- fast, convenient online submission

- thorough peer review by experienced researchers in your field

- rapid publication on acceptance

- support for research data, including large and complex data types

- gold Open Access which fosters wider collaboration and increased citations

- maximum visibility for your research: over $100 \mathrm{M}$ website views per year

At $\mathrm{BMC}$, research is always in progress.

Learn more biomedcentral.com/submissions 